EDUCATIONAL

-RESOURCE

Volume 12 lssue 42020

DOI: 10.21315/eimj2020.12.4.7

ARTICLE INFO

Submitted: 29-01-2020

Accepted: 04-05-2020

Online: 30-12-2020

\title{
"Should I Be Continued Breathing?": Management of Life Limiting Condition from Islamic Ethical Perspective
}

\author{
Siti Nur Haidar Hazlan, Nur Aishah Mazlan, Farah Syazana Kabir \\ Ahmad, Fahisham Taib
}

Hospital Universiti Sains Malaysia, 16150 Kubang Kerian, Kelantan, MALAYSIA

To cite this article: Hazlan SNH, Mazlan NA, Kabir Ahmad FS, Taib F. "Should I be continued breathing?": management of life limiting condition from Islamic ethical perspective. Education in Medicine Journal. 2020;12(4):47-51. https://doi.org/10.21315/eimj2020.12.4.7

To link to this article: https://doi.org/10.21315/eimj2020.12.4.7

\section{ABSTRACT}

Spinal muscular atrophy (SMA) is one of the most recognised life-limiting conditions in paediatric palliative care. Despite the advancement of medical technology, many children with severe SMA die early. Often, managing physicians are trapped in dilemma whether to go all-out treating these patients or to be more conservative using palliative approach, knowing our limited resources and the futility of the treatment outcome. This article discusses the challenging aspect of managing these patients by using Islamic medical ethics to resolve this dilemma.

\section{Keywords: Spinal muscular atrophy, Islamic ethics, Palliative care, End of life}

\section{CORRESPONDING AUTHOR}

Dr. Fahisham Taib, Hospital Universiti Sains Malaysia, 16150 Kubang Kerian, Kelantan, Malaysia | Email: fahisham@gmail.com

\section{INTRODUCTION}

Treating a baby with life limiting condition such as spinal muscular atrophy (SMA) poses a challenge to the managing doctors. The SMA disease spectrum is based on the presence of the defective genes. The younger the age of presentation, the more guarded the prognosis of such patients. Many ethical issues can be discussed ranging from screening, diagnosis, management and even end of life. Managing the case in the context of Islamic ethics requires a world view on the purpose of shariah (law of Islam) and the knowledge of fiqh (legal maxim of Islam).

\section{CASE}

A one-month old Malay boy presented to tertiary centre with lifelessness and reduced motor activities. His mother noticed the floppiness of his upper and lower limbs with a low pitch cry since birth. Clinical examination confirmed reduction of his tone, deep tendon reflexes and sucking effort. $\mathrm{He}$ also has positive rag-doll posture, tongue fasciculation and peripheral hypotonia consistent with lower motor neuron signs, and the diagnosis was confirmed following the genetic testing. Parent are non-related. He was delivered by spontaneous vaginal delivery with good condition and the birth weight of $3.2 \mathrm{~kg}$. During the admission, he developed chest infection needing intubation and ventilation. 
He was successfully weaned into high flow nasal oxygen (optiflow) following extubation but unsuccessful attempts to wean him off the oxygen. Collective decision was made against long term ventilation due to his poor prognostication. He succumbed to his illness after a few weeks on optiflow.

\section{CASE DISCUSSION}

Western bioethics remained an essential virtuous pillar used in our daily clinical practice. This would include principles universally used; such as beneficence (the ability to do good), non-maleficence (need to avoid harm), justice and autonomy (right of self-determination). These principles would be generally applied in many ethically challenging cases in the medical practice. Many dilemmas arise from the difficulty and unclear decisionmaking in managing the patient. The child's inability to act autonomously, and thus, relying full decision by proxy (by their parents) also complicates the matter further. Consideration on culture, financial and customary practices may be important aspect of the decision.

In the scenario given, there are couple of questions need to be answered:

a. Is it right to escalate respiratory support (non-invasive ventilator [NIV] support) when the condition is considered futile?

b. Is it right for parent or healthcare professional to decide on what is the patient's best interest in non-verbal children?

c. Is using respiratory support considered as the best care or does it cause more suffering to patient?

Islam considers life as sacred and a trust from Allah. The preservation of life is considered paramount in Islam and the sanctity of life has been expressed clearly in following Quranic verse;

\begin{abstract}
We ordained for the children of Israel that if anyone killed a person, unless it be for murder or for spreading mischief in the land, it would be as if he killed the whole of mankind. And if anyone saved a life, it would be as if he saved the life of a whole people. (5:32)
\end{abstract}

However, Islam also recognises that death is inevitable part of human existence. Prolongation of life may not be what Islam permits in the final stage of a human terminal illness.

\section{Every soul shall have a taste of death: In the end to us shall you be brought back. (29:57)}

The Muslim doctors must have the faith in Allah and destiny, the conviction cure for every disease, acquiring adequate medical knowledge, aware of his mission in this world, having morality on the decision made deriving from Islamic laws and Islamic medical ethics. In terminally ill paediatric patients, the physician and patient or surrogate should formulate the appropriate goals of therapy and how aggressive treatment should be. Explanation on the advantages and disadvantages of each procedure, treatment and intervention should be directed towards relieving of the suffering and improving quality of life. Balancing between alleviating the suffering and their right to receive appropriate medical treatment until the end of their life is crucial part of ethical justification. Frequent evaluation on patient's medical status is essential when applying the principle of non-maleficence. It is the duty of managing physicians to ensure the right of the patient is respected and fulfilled, together with the family preferences. Strategies employed include allowing patient and family to explore medical questions with the medical team, family's feelings, analgesic coverage and support, to alleviate anxiety. 


\section{ISLAMIC PERSPECTIVE}

In Islamic perspective, 'ilm (knowledge) is essential for decision-making, therefore all Muslims are expected to make decision according to knowledge that they possessed (1). Muslims are also required to seek knowledge with the right person or the expert in their field to allow appropriate decision-making (2). Islamic ethics covers the Maqasid al-Shariah (purpose or objectives of law) which have six guiding principles - protection of religion, maintenance of life, protection of an individual's freedom or belief, maintaining the intellect, preservation of honour and integrity, and protection of property. Anything that preserves one of these six purposes is regarded as beneficial, while anything that contributes to its detriment is considered immoral (3). These principles are supported with Qawa'id al-Fiqhiyyah (principle of law) and Fiqh al-Awwaliyyat (law of prioritisation) (4). All of the principles and teaching in Islam agree that individuals have their own rights as long as they understood and have full knowledge from the experts about the consequences of their decision. Extrinsic value may influence the decision-making, and vulnerable groups like children have to depend on surrogate decision (5).

In our scenario, the child is on the verge of dying. Guided decision by non-paternalistic actions should be done according to the goals of care. Death of a child may impact the family psychologically and spiritually. Support for the living family members is essential part to allow acceptance with the loss, life closure and dignity of care. Preparation for good communication and trust building between the managing team and the family should entail on what is realistic and achievable aims. When death becomes inevitable, the patient should be allowed to die without unnecessary suffering or prolongation of life.

Escalating treatment such as using respiratory support remains a heated debate among the modern scholars. On one hand, this has been considered as a standard care for children with SMA, hence prolonging patient's life. On the other hand, in less resourceful country like Malaysia, this would signify a challenge to the managing team. Managing SMA using modern technology or equipment without proper support to the family may not be beneficial despite having internationally recognised guideline and standard of care. The use of NIV in our setting may be unjustified due of various reasons - related to family readiness, availability of supporting team in the community and inevitable death as the final outcome. Does that mean the introduction of NIV which potentially prolonging the patient's life span without significant quality of life is acceptable? Should he be allowed to die naturally knowing the futility of the medical effort? Palliative care is about finding the right balance between correctness of the decisionmaking and having control of the distressing symptoms - physically, psychosocially, spiritually and emotionally. Medical treatment that can reverse clinical condition should be continued, but attempts to sustain artificial life support for life continuity without good quality of life should be ignored. Withdrawal of the intervention should be judiciously made if patient is on mechanical ventilator support (6), if the outcome is futile.

\section{ISLAMIC ETHICS}

In non-verbal children, legal parent act as surrogate to make the decision on behalf of the minor. Is it best interest to allow the child to die naturally? Preserving life is part of Maqasid al-Shariah or purpose of the law. However, using Islamic legal maxim (Qawa'id al-Fiqhiyyah), matters are judged in light of the intention behind them (first legal maxim). Intention to leave a natural process to occur mainly stem from the futility of the condition. SMA (Type 1) is a known genetic condition which has a rather short life span. Consideration to support 
him using NIV may require physician to have strong reason behind the decision. The second legal maxim stressed on establishing a certainty in our decision-making (7). This is supported by knowing the disease trajectory. Introducing new equipment may help to prolong patient's life, but this does not tailor the finality of the disease process. If there is uncertainty of the outcome, all effort should be made to ensure the patient is treated well medically.

In the third legal maxim, it is stated that hardship begets easiness afterwards. Any condition that will seriously impair physical and mental health, effort should be made to relieved the situation. NIV was not offered in our case, due to financial and infrastructure constraint of our setting. The optiflow or high flow oxygen therapy was given as an alternative. This has bought some time for the patient to have a quality time with the family members, thus creating a long lasting memory. Unfortunately, this also has uncertainty effect of patient's suffering from the weakness of his respiratory muscle.

If we use fourth legal maxim, harm must be eliminated. Is it harmful by not doing any intervention when suffering for this child is greater than survival? Harm not to treat with medication or respiratory support eventually will lead to death, similarly, harm of trying with equipment will also end with death. In this scenario, both ways have a similar end point. If the decision is based on financial repercussion, then allowing the natural process to occur may be acceptable. If family wishes to create a precious moment with the patient, prolonging life without intentional harm or extending the suffering may be the right option to follow. Patient's life will end quickly if no intervention instituted. In this circumstances, mutual decision between the family and physician allows a much better route for resolution.

In the fifth legal maxim, customary is what considered as uniform, widespread, common and predominant. Local custom has to be taken into consideration, provided it did not contradict the shariah legality (3). It is a common practice that intervention is not preferred in this case in view of financial and lack of support by the governing body and various parties. If parent insisting to go beyond on what has been agreed, further study is needed to see the viability of such intervention among children with this condition. Saving lives is part of important aspect of shariah. But in this scenario, death cannot be averted. Each case needs an individualised approach and consideration. Many of the ethically challenging cases are far from having a definitive answer. Even if this SMA child is ventilated, the issue of suffering and quality of life could not be answered. This is difficult since the paradigm of the children cannot be undertaken, but parent who know their children, have some say on what they feel and would mean to them when all the efforts are achieved.

\section{CONCLUSION}

End of life for a baby with SMA requires preparation by the family to face the certainty of death. Even though support such as NIV machine is available, there are grey area around the decision-making and final goals of care. There are questions about how to achieve good quality of life, reducing suffering as well as to ensure of having a peaceful ending. Using Islamic legal maxim and principles, derivatives and source of decision could have pinpoint the appropriate justification based on motives, certainty, injury, hardship and customary practice.

\section{REFERENCES}

1. Aksoy S, Tenik A. The four principles of bioethics as found in 13th century Muslim's scholar Mawlana's teachings. BMC Medical Ethics. 2002;3(1):E4. https://doi. org/10.1186/1472-6939-3-4

2. Al-Quran. Surah al-Anbiya' (21:7). 
3. Chamsi-Pasha H, Ali M. Principles of Islamic Medical Ethics. J British Islamic Medical Assoc. 2019; 1(1):3-7.

4. Saidun S. Islamic biomedical ethics: an overview. PERINTIS E-journal. 2015;5(1):45-7.

5. Varelius J. The value of autonomy in medical ethics. Med Health Care Philos. 200;9(3):377-88. https://doi.org/10.1007/ s11019-006-9000-z
6. Athar S, Fadel HE, Ahmad WD, Haque $M$, Nagamia HF, Hathout $H$, et al. Islamic medical ethics: the IMANA perspective. JIMA. 2005;37:33-42. https://doi. org/10.5915/37-1-5528

7. Mustafa Y. Islam and the 4 principles of medical ethics. J Medical Ethics. 2013;40(7):479-83. https://doi.org/10.1136/ medethics-2012-101309 